\title{
Prognostic Factors in Patients who Underwent Aneurysmal Clipping due to Spontaneous Subarachnoid Hemorrhage
}

\author{
Metin ORAKDOGEN ${ }^{1}$, Selin TURAL EMON¹, Hakan SOMAY¹, Taner ENGIN¹, Ozkan ATES ${ }^{2}$, Mehmet Zafer BERKMAN³ \\ ${ }^{1}$ Haydarpasa Numune Training and Research Hospital, Department of Neurosurgery, Istanbul, Turkey \\ ${ }^{2}$ Istanbul Esenyurt University, Esencan Hospital, Department of Neurosurgery, Istanbul, Turkey \\ ${ }^{3}$ Acibadem University, School of Medicine, Department of Neurosurgery, Istanbul, Turkey
}

\section{ABSTRACT}

AIM: Despite technical and medical advances, aneurysmal subarachnoid hemorrhages (SAH) continue to be a challenging pathology, associated with high rates of morbidity and mortality. In this regard, a definition is required of the various prognostic indicators of an $\mathrm{SAH}$. The aim of the present retrospective study is to examine the various prognostic factors of the clinical outcomes of the patients who underwent a neurosurgical clipping of aneurysms due to aneurysmal SAH.

MATERIAL and METHODS: The data of 104 patients that had suffered an aneurysmal SAH were analyzed. The baseline demographic, clinical and radiological data were all analyzed. The prognostic study was derived from an analysis of these variables. Relationship between prognostic factors and outcome was evaluated by univariate and logistic multivariate regression analysis.

RESULTS: This study has identified unfavorable outcomes on the Glasgow Outcome Scale at discharge after the surgical treatment of aneurysmal SAH associated with increased age, poor World Federation of Neurosurgical Societies (WFNS) grade on admission, higher Fisher's grade on admission computed tomography scan, larger aneurysm, and clinical vasospasm. In a multivariate logistic regression analysis, age, high WFNS grade, positive clinical vasospasm and size of aneurysm were found to be independent risk factors for mortality. The presence of hydrocephalus, number of aneurysms, positive risk factors, and the presence of Doppler vasospasm did not reach statistical significance.

CONCLUSION: The most important prognostic factors in patients undergoing surgery due to aneurysmal subarachnoid hemorrhage were WFNS grade, age, size of aneurysm and clinical vasospasm.

KEYWORDS: Aneurysmal clipping surgery, Aneurysmal subarachnoid hemorrhages, Morbidity, Mortality, Prognostic factor

\section{INTRODUCTION}

$\mathrm{D}$ espite the technical and medical advances, aneurysmal subarachnoid hemorrhage (SAH) continue to be a challenging pathology, associated with high rates of morbidity and mortality. The current treatment of the condition involves the early repair of the aneurysm to prevent re-bleeding and associated problems, including cerebral vasospasm, hydrocephalus, electrolyte imbalances, infections and seizures.

In this regard, a definition is required of the various prognostic factors of an SAH. The factors affecting the outcomes of aneurysmal SAHs have been investigated in several studies.

The aim of the present retrospective study is to examine the various prognostic factors of the clinical outcomes of 104 patients who underwent a neurosurgical clipping of aneurysms due to aneurysmal SAH between 2008 and 2014.

\section{MATERIAL and METHODS}

The data of 104 patients that had suffered an aneurysmal SAH were analyzed. The patients were recruited between 2008 and 2014 at the Neurosurgery Clinic of Haydarpasa Numune Training and Research Hospital. 
Evidence of SAH from a computerized tomography (CT) scan and the presence of an angiographically-confirmed saccular aneurysm as the cause of the hemorrhage constituted the inclusion criteria for the study.

Patients with traumatic SAHs, or fusiform, mycotic, traumatic or unruptured aneurysms, or those with SAH from an unknown etiology were excluded. Posterior system aneurysms were treated with endovascular techniques in our department. Patients who had undergone endovascular therapy were also excluded.

The baseline demographic and clinical data included age; gender; complaint on admission, especially the presence of loss of consciousness at ictus; World Federation of Neurosurgical Societies (WFNS) grade at admission; time from ictus to admission and ictus to surgery; concomitant diseases/risk factors, and a previous history of SAH; presence of hydrocephalus at the initial CT scan; Fisher grade at initial CT scan; Willis anomalies in a cerebral angiography; number of aneurysms; aneurysm localization; size of aneurysm; presence of doppler vasospasm; postoperative complications, including symptomatic vasospasm, cerebral infarction, hydrocephalus, cerebral hemorrhage, central nervous system (CNS) or systemic infections; pulmonary embolism; postoperative length of hospital stay; and Glasgow outcome score (GOS) were all analyzed. The prognostic study was derived from an analysis of these variables. We chose an arbitrary cut-off age of 55 for statistical analyses.

The WFNS scale was used to grade the initial neurological condition (8), while the initial CT appearance was used to classify radiologically the severity of $\mathrm{SAH}$ according to Fisher et al. (9).

When multiple aneurysms were detected, the aneurysm most likely to have ruptured, which was determined from the blood pattern in the CT scan and the cerebral angiography findings, with only ruptured aneurysms taken into account.

The patients underwent a lumbar puncture (LP) or external ventricular drainage (EVD) upon the detection of hydrocephalus on the initial cerebral CT.

A diagnostic cerebral angiography was performed as early as possible after admission. The maximum angiographically demonstrated diameter of the ruptured aneurysm was recorded. Ruptured aneurysms were treated promptly upon the obtaining of a diagnostic cerebral angiography. In the presence of evidence of an intracranial hematoma with mass effect, the patient was operated on in emergent surgery with or without a cerebral angiography.

All patients underwent surgery at the earliest opportunity. Taking the day of the hemorrhage as day 0 , surgical intervals were defined either as immediate (day 0 ), early (days $1-3$ ), intermediate (days 4-14) or late (days after 14).

Surgical treatments involved the appropriate standard craniotomy for the clipping of the aneurysm. Post-surgery, all patients were admitted to the neurosurgical intensive care unit, and almost all underwent $3 \mathrm{H}$ therapy (hypervolemia, hypertension and hemodilution) to maintain central venous pressure at the level of $10 \mathrm{cmH}_{2} \mathrm{O}$ and systolic blood pressure above $150 \mathrm{mmHg}$, and were administered nimodipine orally or via nasogastric tube in intubated patients $(4 \times 30 \mathrm{mg} / \mathrm{day})$ for three weeks to prevent vasospasm in the postoperative period. Steroids and anticonvulsant medicines were routinely administered in the preoperative and postoperative periods.

Transcranial Doppler (TCD) velocities were recorded as a matter of routine after admission and/or postoperatively in all patients. Furthermore, flow velocities in the middle cerebral artery, the anterior cerebral artery, and the intracranial internal carotid artery were measured using the transtemporal approach. Mean TCD velocity of $120 \mathrm{~cm} / \mathrm{sec}$ in the investigated territories was defined as a Doppler vasospasm.

A diagnosis of clinical vasospasm was made in the event of the development of focal neurological signs or deterioration in the level of consciousness, or both, and was confirmed with a TCD. A 2-point decrease in the score of the Glasgow Coma Scale (GCS) was considered a significant deterioration. Other causes of deterioration, including electrolyte imbalance, hydrocephalus, re-bleeding, postoperative brain swelling or hemorrhage, seizures and CNS infections were ruled out. The outcomes were assessed at discharge using the 5-point GOS, in which a GOS of 1 indicates mortality (15).

\section{Statistical Analysis}

The NCSS (Number Cruncher Statistical System) 2007 \& PASS (Power Analysis and Sample Size) 2008 Statistical Software (Utah, USA) programs were used for the statistical analysis. Student's t-test was used for the comparison of quantitative data that showed a normal distribution, while a Mann-Whitney U-test was used to compare parameters with abnormal distribution. Fisher-Freeman-Halton and Yates Continuity Correction (Chi-square with Yates correction) tests were used for the comparison of qualitative data. Finally, a logistic regression analysis was used to evaluate the multivariate effects of the parameters on mortality. The level of significance was set at $p<0.01$ and $p<0.05$.

\section{RESULTS}

This study was carried out in the Neurosurgery Clinic of Haydarpasa Numune Training and Research Hospital between January 2008 and February 2014 on a total of 104 cases. All patients' data were summarized in Tables I- III; Figure 1.

When age, loss of consciousness, WFNS grade, Fisher grade, size of aneurysm, clinical vasospasm and effects of operation in the immediate stage (Day 0) after SAH were evaluated in a Backward Stepwise Logistic regression analysis, the model was found to be significant, and the coefficient of determination was excellent $(90.4 \%)$. The effect of WFNS grade on mortality $(\mathrm{OR}=88.809,95 \% \mathrm{Cl}: 8.60-916.15)$; for the effect of clinical vasospasm (OR $=46.093,95 \% \mathrm{Cl}: 4.14-512.10)$; for the effect of age, $(\mathrm{OR}=3.596,95 \% \mathrm{Cl}: 1.096-1.64)$; and for the effect of the size of the aneurysm above $7 \mathrm{~mm},(\mathrm{OR}=4.592,95 \%$ $\mathrm{Cl}: 1.198-23.467)$. Age, WFNS grade, clinical vasospasm, and size of aneurysm were independent risk factors for mortality. The multivariate effects of other variables were not significant (Tables IV, V). 


\section{DISCUSSION}

The rupture of a cerebral aneurysm is the primary cause of spontaneous SAH. Subarachnoid hemorrhages continue to be associated with poor prognosis, despite improvements in its diagnosis and treatment. Mortality and morbidity is high in such cases, and the predictive factors of a poor prognosis remain unknown. The factors affecting the outcomes after $\mathrm{SAH}$ have been investigated in several studies.

Admission WFNS grade, the presence of a clinical vasospasm, Fisher's grade, age, gender, timing of surgery, history of hypertension, intraoperative rupture, the development of hydrocephalus, time of admission after SAH, aneurysm location and size, presence of intracerebral or intraventricular hemorrhage, and blood pressure at admission are among the prognostic factors that have been investigated, and some of these have gained wide acceptance, while controversy still exists regarding the others.

\section{Age \& Gender}

Age is an important factor influencing the outcome of patients, and has a prognostic importance in the disease. A more advanced age indicates an unfavorable outcome $(2,7,16$ 18,32).

Schöller et al. (31) reported that patients aged $<70$ years with an initial WFNS score of I-III showed the best clinical recovery rates. The outcome clearly worsened with increasing age, and age was one of the strongest predictors of mortality and a

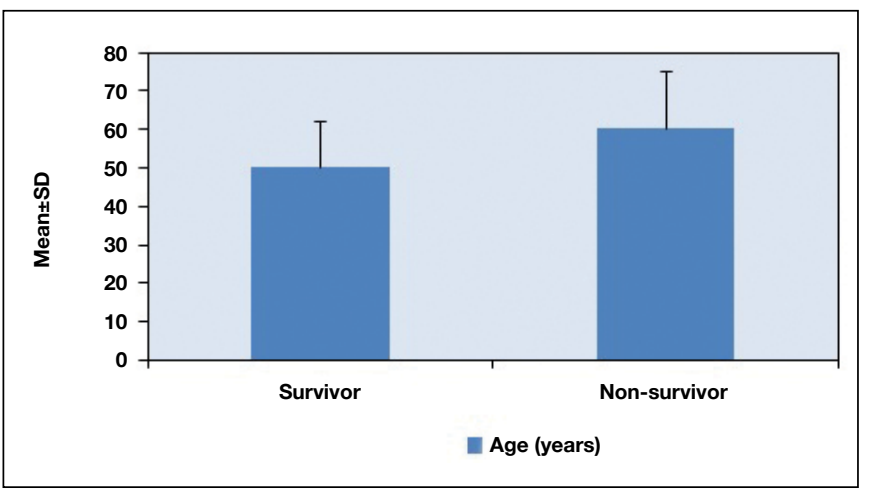

Figure 1: Age distribution of the cases according to mortality. poor outcome. They showed that age itself contributes to a negative outcome, independent of the condition at admission and the presence of any pre-existing medical diseases. Chotai et al. found in a univariate regression analysis of the outcomes at discharge that the age of the patient at the time of presentation and male gender were predictors of an unfavorable outcome. A multivariate regression analysis showed the independent effects of gender on the outcome at discharge in 108 young adult patients (6). Although there are also reports suggesting that age and sex have no prognostic value $(3,11,14,20)$.

In the present study, being at or above the age of 55 was found to be an independent risk factor for mortality and there was no statistically significant difference between genders in terms of mortality.

\section{Risk Factors}

Hypertension, smoking, a positive family history for SAH and hypercholesterolaemia were found to be major risk factors in the development and rupture of cerebral aneurysms although there is a lack of agreement as to whether they are a prognostic factors in outcomes $(17,34)$. Based on a multivariate exact regression analysis, hypertension was found to be a predictor of outcome at a mean two-year follow up (6). Elevated blood pressure and the presence of a preexisting medical illness are predictive of mortality (16). Disney et al. (7) reported that initial systolic blood pressure had relative importance as a prognostic factor in outcomes, although other authors claim that a history of essential arterial hypertension is not related to outcome $(11,14,20)$. In the study by Ohman et al. (22) a history of hypertension was reported to be a prognostic factor for cerebral infarction in patients after aneurysmal SAH.

The overall rate of risk factors, including hypertension, heart disease, lung disease, diabetes mellitus and smoking was $43.27 \%$ in our patients, and hypertension was the most commonly reported preexisting illness (38.46\%). We found no statistically significant difference between the rates of risk factors in terms of mortality.

\section{Localization and Diameter of Aneurysm}

Shiue et al. (33) point out that the size of a ruptured aneurysm is an important determinant of outcome in $\mathrm{SAH}$, and should be used as a prognostic parameter in directing management.

Table I: Evaluation of the Demographic Features of Cases According to Mortality

\begin{tabular}{|c|c|c|c|c|}
\hline & & \multicolumn{2}{|c|}{ Mortality } & $\mathbf{p}$ \\
\hline Age: Mean+SD & & $50.46 \pm 11.90$ & $60.36 \pm 15.07$ & ${ }^{a} 0.006^{* *}$ \\
\hline \multirow{2}{*}{ Age (years) } & $<55$ & $56(62.2 \%)$ & $6(42.9 \%)$ & \multirow{2}{*}{-} \\
\hline & $\geq 55$ & $34(37.8 \%)$ & $8(57.1 \%)$ & \\
\hline Gender: n (\%) & Female & 45 (50.0\%) & 6 (42.9\%) & \\
\hline
\end{tabular}

aStudent's t-test, ' $Y$ Yates continuity correction test, $p<0.01^{\text {** }}$ 
Table II: Overall Distribution of Descriptive Features $(n=104)$

\begin{tabular}{|c|c|c|c|}
\hline \multirow{2}{*}{ Age (years) } & \multicolumn{2}{|l|}{ Min-Max (Median) } & $16-84(51.5)$ \\
\hline & \multicolumn{2}{|l|}{ Mean $\pm S D$} & $51.79 \pm 12.75$ \\
\hline \multirow{2}{*}{ Age-Male $(n=53)$} & \multicolumn{2}{|l|}{ Min-Max (Median) } & $16-84(51)$ \\
\hline & \multicolumn{2}{|l|}{ Mean $\pm S D$} & $50.19 \pm 11.64$ \\
\hline \multirow{2}{*}{ Age-Female $(n=51)$} & \multicolumn{2}{|l|}{ Min-Max (Median) } & $16-81(54)$ \\
\hline & \multicolumn{2}{|l|}{ Mean \pm SD } & $53.45 \pm 13.72$ \\
\hline \multirow{2}{*}{ Age (years) } & \multicolumn{2}{|l|}{$<55$} & $62(59.6 \%)$ \\
\hline & \multicolumn{2}{|l|}{$\geq 55$} & $42(40.4 \%)$ \\
\hline \multirow{2}{*}{ Gender } & Male $\quad n(\%)$ & & $53(51.0 \%)$ \\
\hline & \multicolumn{2}{|l|}{ Female n (\%) } & $51(49.0 \%)$ \\
\hline \multicolumn{3}{|l|}{ Loss of consciousness n (\%) } & $44(42.3 \%)$ \\
\hline \multicolumn{3}{|l|}{ Risk factors n (\%) } & $45(43.3 \%)$ \\
\hline \multicolumn{3}{|l|}{ Hydrocephalus n (\%) } & $58(55.8 \%)$ \\
\hline \multicolumn{3}{|l|}{ Anomalies of the Circle of Willis n (\%) } & $64(61.5 \%)$ \\
\hline \multicolumn{3}{|l|}{ Complications n (\%) } & $53(51.0 \%)$ \\
\hline \multirow[t]{2}{*}{ Number of Aneurysms } & Single Aneurysm & $\mathrm{n}(\%)$ & $84(80.8 \%)$ \\
\hline & Multiple Aneurysms & $\mathrm{n}(\%)$ & $20(19.2 \%)$ \\
\hline \multirow{3}{*}{ Localization of Aneurysms } & $\underline{\text { ICA }}$ & $\mathrm{n}(\%)$ & $27(26.0 \%)$ \\
\hline & ACoA & n (\%) & $45(43.3 \%)$ \\
\hline & MCA, ACA & $\mathrm{n}(\%)$ & $32(30.8 \%)$ \\
\hline \multirow{2}{*}{ Size-Diameter of Aneurysm (mm) } & \multicolumn{2}{|l|}{ Min-Max (Median) } & $1.8-20.0(7)$ \\
\hline & \multicolumn{2}{|l|}{ Mean \pm SD } & $7.21 \pm 3.45$ \\
\hline \multirow{2}{*}{ Operation After SAH (Day) } & \multicolumn{2}{|l|}{ Min-Max (Median) } & $0-51(2)$ \\
\hline & \multicolumn{2}{|l|}{ Mean $\pm S D$} & $4.53 \pm 6.89$ \\
\hline \multirow{4}{*}{ Operation After SAH Stage } & Immediate (Day 0) & $\mathrm{n}(\%)$ & $8(7.7 \%)$ \\
\hline & Early (Days 1-3) & n (\%) & $57(54.8 \%)$ \\
\hline & Late (Days after 14) & $\mathrm{n}(\%)$ & $6(5.8 \%)$ \\
\hline & Intermediate (Days 4-14 ) & $\mathrm{n}(\%)$ & $33(31.7 \%)$ \\
\hline \multirow{2}{*}{ Length of Hospital Stay After Op (Day) } & Min-Max (Median) & & $7-85(11)$ \\
\hline & Mean \pm SD & & $16.32 \pm 13.35$ \\
\hline 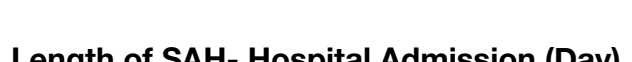 & Min-Max (Median) & & $0-26(0)$ \\
\hline Length OI SAח- nOSpItal Aamission (Day) & Mean \pm SD & & $2.15 \pm 4.48$ \\
\hline W & Low: n (\%) & & $86(82.7 \%)$ \\
\hline vrins scale & High: n (\%) & & $18(17.3 \%)$ \\
\hline & $<1 \mathrm{~mm}$ & & $38(36.5 \%)$ \\
\hline Fisher's grade & $>1 \mathrm{~mm}$ & & $30(28.8 \%)$ \\
\hline & Bleeding & & 36 (34.6\%) \\
\hline
\end{tabular}


An aneurysm larger than $10 \mathrm{~mm}$ is associated with a poorer progression, and size had relative importance as a prognostic factor for outcome $(7,24)$. Chotai et al. (6) also found that the size of the aneurysm and the presence of multiple aneurysms were associated with unfavorable outcomes. In young adult patients, the size of an aneurysm and the presence of multiple aneurysms were found to be predictors of outcome at mean two years of follow up (6). Similar to other studies, in the logistic regression analysis, an aneurysm size above 7 $\mathrm{mm}$ was found to be an independent risk factor for mortality but findings were showed the number of aneurysms did not differ significantly in terms of mortality. We detected the rate of distally located aneurysms; middle cerebral artery (MCA), anterior cerebral artery (ACA) was significantly higher among the non-survivors.

Table III: Evaluation of Parameters according to Mortality

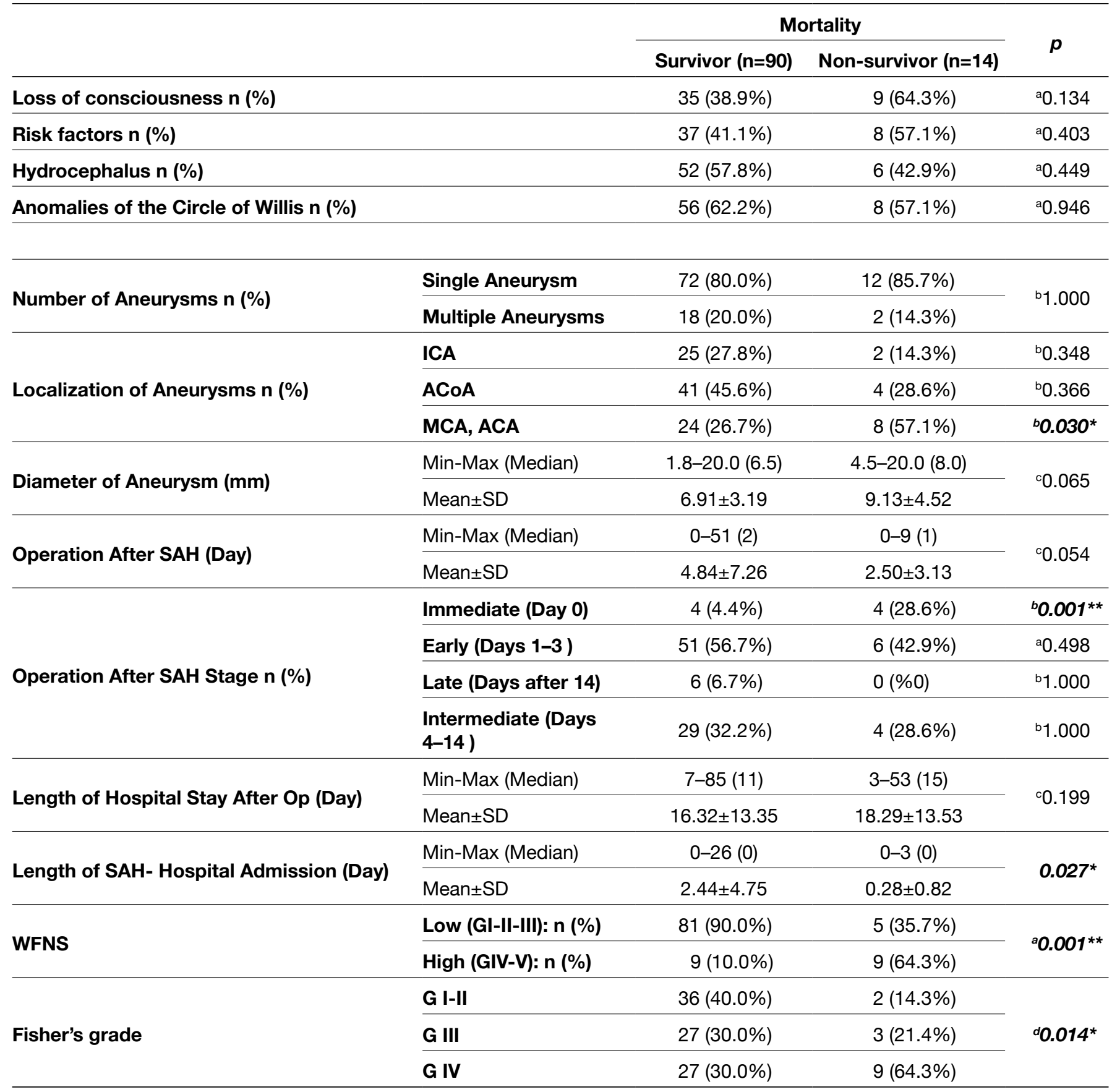

aYates Continuity Correction, ${ }^{b}$ Fisher's Exact Test, ${ }^{c}$ Mann-Whitney $U$ Test, ${ }^{d}$ Fisher Freeman Halton, $p<0.05^{*}, p<0.01^{* *}$, ACoA: Anterior communicating artery, MCA: Middle cerebral artery, ACA: Anterior cerebral artery. 
Table IV: Evaluation of Doppler Vasospasm and Clinical Vasospasm Parameters in Terms of Mortality

\begin{tabular}{lccc}
\hline & \multicolumn{3}{c}{ Mortality } \\
\cline { 2 - 3 } & Survivor $(\mathbf{n = 9 0 )}$ & Non-survivor $(\mathbf{n = 1 4 )}$ & $\mathbf{p}$ \\
\cline { 2 - 3 } Doppler Vasospasm & $\mathbf{n}(\%)$ & $\mathbf{n}(\%)$ & $\mathbf{1 . 0 0 0}$ \\
\hline Clinical Vasospasm & $33(36.7 \%)$ & $5(35.7 \%)$ & $0.021^{*}$ \\
\hline
\end{tabular}

ayates Continuity Correction, ${ }^{b}$ Fisher's Exact Test.

Table V: Logistic Regression Analysis of Risk Factors Associated with Mortality

\begin{tabular}{|c|c|c|c|c|}
\hline & \multirow{2}{*}{$\mathbf{p}$} & \multirow{2}{*}{ Odds } & \multicolumn{2}{|c|}{ 95.0\% C.I. for EXP(B) } \\
\hline & & & Lower & Upper \\
\hline Age (years) $(\geq 55)$ & $0.046^{\star}$ & 3.596 & 1.096 & 17.63 \\
\hline Size of Aneurysm $(>7.0 \mathrm{~mm})$ & $0.047^{\star}$ & 4.592 & 1.198 & 23.467 \\
\hline WFNS (high) & $0.001^{* *}$ & 88.809 & 8.609 & 916.152 \\
\hline Clinical Vasospasm (positive) & $0.002^{\star \star}$ & 46.093 & 4.149 & 512.105 \\
\hline
\end{tabular}

\section{Operation Stage}

There is a lack of consensus in the literature related to the effect of the operation stage on prognosis. The timing of surgery is not associated with the outcome or have a relatively small influence on the outcome $(14,20,29)$. There was no significant difference between incidences of cerebral infarcts in patients who underwent emergent surgery (22).

In the study of Haley et al. (12); in contrast to the results of the overall study, the prognosis was better in the group who were planned to undergo surgery on days $0-3$ when compared to the patients who were planned to undergo surgery on days 11-32. The outcomes were poorer when surgery was planned for the 7-10-day period, because of the greatest risk for symptomatic vasospasm.

An evaluation of the patients in terms of the stage of disease on the day of operation revealed that $62.5 \%$ of the patients were treated within the first 72 hours after the onset of $\mathrm{SAH}$, 31.73 percent between days 4 and 14 and $5.77 \%$ had surgery planned 14 days in advance. Of the total, eight patients had a significant hematoma and underwent emergency surgery.

Of the cases, $62.5 \%$ were operated on in the early period, $31.73 \%$ were operated upon in the intermediate period, and $5.77 \%$ underwent their operation in the late period. Of the cases operated on in the early period, eight underwent operations on Day 0 , and four of these cases were non-survivors. All cases that underwent operations on Day 0 were of WFNS Grade 4-5 and Fisher Grade 4, and underwent emergent surgery. Of these cases, two underwent surgery due to findings of herniation without first obtaining an angiography. The distribution of operation stages after SAH was significantly different in terms of mortality. The rate of mortality was significantly higher in the Day 0 period, although the rate of mortality did not differ significantly from the other stages of disease.

\section{Hydrocephalus}

The authors suggest that the development of hydrocephalus is not associated with outcome $(14,20)$. Schöller et al. (31) reported hydrocephalus to be the weakest predictor of outcome, while Lagares et al. (18) reported that the presence of hydrocephalus was related to a poor outcome, although it turned out to be insignificant.

We found the rate of hydrocephalus did not differ significantly in terms of mortality. Of the cases that were found to have hydrocephalus, seven underwent ventriculoperitoneal (VP) shunting, four required EVDs, and five were controlled through drainage via an LP and other showed spontaneous regression. The rate of hydrocephalus that required VP shunting was $12 \%$.

\section{Loss of Consciousness (LOC)}

The clinical degree of LOC is favored as a brief evidence for predicting the probability of an unfavorable outcome after aneurysmal SAH (10). The period of loss of consciousness indicates global ischemia. Hop et al. (13) claim that LOC is a strong predictor of the occurrence of $\mathrm{DCl}$.

When the relationship between loss of consciousness and vasospasm was evaluated, the rate of loss of consciousness was found to be $36.8 \%$ in the presence of vasospasm, and $45.5 \%$ in its absence. We showed that LOC alongside the presence of vasospasm did not differ significantly.

\section{Fisher Grade}

It has been widely accepted that a high Fisher grade indicates a poor prognosis $(11,20,24,32)$. The amount of blood in the subarachnoid space is closely related to the occurrence of vasospasms. The thickness of blood clots identified during CT scans can be considered a good predictor of outcome $(22,25,27)$. Fisher grade, intracranial hematoma volume and amount of intraventricular hemorrhage have all been related to poor outcomes (18). 
The thickness of the subarachnoid hemorrhage clot in a computerized tomography was found to be another good predictor of mortality (16). The role of the amount of extravascular blood and that of clinical grade were reported as independent prognostic factors of symptomatic vasospasm occurrence with a further multivariate analysis (5). In contrast, Jamjoom et al. (14) reported that the presence of subarachnoid and intraventricular blood in CT did not reach a statistical significance. Mortality rate was found to be significantly higher among patients with Fisher Grade III and IV in our cases.

\section{Vasospasm}

Many studies have provided evidence of the value of vasospasm as a poor prognostic factor, and have evaluated the development of symptomatic vasospasm as a potential risk factor in worsening the clinical outcome $(16,24,26,29)$.

At ages below 20, the amount of SAH and clinical grade has been associated with a higher risk of vasospasm (26). The presence of angiographic vasospasm at admission is a significant poor prognostic factor of outcome $(14,27)$.

Transcranial Doppler is a common approach for following the course of a vasospasm after a $\mathrm{SAH}$, but its ability to predict clinical deterioration or infarction from delayed cerebral ischemia (DCl) remains controversial. Carrera et al. (4) reported that increased TCD flow velocities denote only a mild incremental risk of $\mathrm{DCl}$ after $\mathrm{SAH}$. They obtained $\mathrm{DCl}$ occurred in $21 \%$ of patients. Delayed cerebral ischemia and delayed cerebral infarction was carried different prognostic values in an aneurysmal SAH (35).

Samaha et al. (30) specified that the main prognostic factors in aneurysmal SAH were the preoperative neurological state and the occurrence of an arterial vasospasm. A symptomatic cerebral vasospasm was diagnosed in $22 \%$ of cases, but only $12 \%$ carried evidence of low density in a CT scan. Symptomatic vasospasm has already been associated with unfavorable outcomes (20). Charpentier et al. (5) disagreed that the occurrence of symptomatic vasospasm was associated with increased mortality, claiming that the $23 \%$ incidence of symptomatic vasospasm was comparable with that found in surgical series.

The rate of Doppler vasospasm did not differ significantly in terms of mortality in our study. A clinical vasospasm occurred in $36.84 \%$ of the patients who had suffered from Doppler vasospasm. The rate of clinical vasospasm differed significantly in terms of mortality.

\section{World Federation of Neurosurgical Societies Grade}

A poor pre-operative WFNS, Hunt and Hess scores indicate an unfavorable outcome. Patients with the highest pre-operative WFNS grade achieve better outcomes $(1,7,11,14,16,20,23,32)$.

Bohnstedt et al. (3) reported that Hunt and Hess grade on admission was to be a primary prognostic factor of outcome. The best clinical recovery was observed in patients aged $<70$ years with a WFNS grade of I-III. Elderly patients who are admitted with a good WFNS score (I-III) benefit from aggressive treatment (31).
The prediction of outcomes after $\mathrm{SAH}$ can be improved by taking into account additional clinical and radiological factors alongside the WFNS scale. These include age, WFNS grade, and history of hypertension, systolic blood pressure on admission, ruptured aneurysm location and size, blood clot thickness on CT scan and angiographic vasospasm on admission. A grading scale using these factors may be created that can predict outcomes more accurately than the WFNS scale $(27,28)$.

Level of consciousness has been regarded as one of the major determinants of outcome after an aneurysmal SAH. Although the level of consciousness is a major determinant of outcome after subarachnoid hemorrhage, there is a lack of consensus on which classification should be used to define it. In the logistic regression model, the level of consciousness defined by the WFNS scale and the presence of global brain hypodensity on the initial CT scan was a significant prognostic factor. The WFNS grading scale was failed to predict significant differences in outcome across various grades. Age and clinical grade on admission are the most important factors influencing the final outcome of patients suffering from aneurysmal SAH (18).

To date, various grading scales have been used to assess prognosis after a $\mathrm{SAH}$, and most are based on the level of consciousness of the patient. However, grading scales that take into account additional factors show higher prognostic efficacy. Ogilvy et al. (21) developed a new grading scheme (Massachusetts General Hospital [MGH] Scale) that applied a simple scoring method to each prognostic factor that was considered relevant, such as the level of consciousness, the age, the quantity of blood in the first CT scan and the size of the aneurysm. In this system, one point is assigned for Hunt and Hess Grade IV or V, a Fisher Scale score of III or IV, an aneurysm size greater than $10 \mathrm{~mm}$, a patient age older than 50 years, and if the lesion is giant ( $>$ or $=25 \mathrm{~mm}$ ) and localized in the posterior circulation. A 5-point grading system (Grades $0-5)$ is created by the summation of the total points.

Patient age, size of aneurysm, severity of SAH (Fisher Scale evaluation of density of blood present as revealed by computed tomography), and clinical condition (Hunt and Hess grade) were each independently and strongly (relative risk $>4$ ) associated with long-term outcome. In addition, there was a trend toward increased risk with larger $(>25 \mathrm{~mm})$ posterior circulation lesions. Lagares et al. (19) was introduced the modified version of the MGH scale, which makes it applicable to every patient suffering from $\mathrm{SAH}$.

We found that the WFNS grade was significantly higher among the non-survivors. In a logistic regression analysis, a high WFNS grade was found to be an independent risk factor for mortality.

Different from previous studies, the present study evaluated the effects of the presence of anomalies of the circle of Willis, the length of hospital stay after operation, and the time interval between SAH and hospital admission on prognosis. The rate of circle of Willis anomalies did not differ significantly in terms of mortality. 
After SAH, 62 cases were admitted to the hospital on the same day, and 10 cases were admitted on Day 1. The time between SAH and hospital admission differed significantly related to the rate of mortality. Time to hospital admission after SAH was significantly lower among the non-survivors. As can be understood from the high WFNS grade of these patients on admission, dispatching patients to the hospital in the shortest time possible after a sudden onset of coma and establishing an early diagnosis can explain the observed statistical significance.

\section{CONCLUSION}

This study has identified unfavorable outcomes on the GOS at discharge after the surgical treatment of aneurysmal SAH associated with increased age, poor WFNS grade on admission, higher Fisher grade on admission CT scan (including intraventricular hemorrhage and intracerebral hemorrhage), larger aneurysm, and symptomatic vasospasm. The most important factors are WFNS grade, age, size of aneurysm and symptomatic vasospasm.

\section{- REFERENCES}

1. Alemán-Rivera A, Camacho-Gómez A: The results of surgical treatment in 100 patients operated on for intracranial aneurysms of the anterior circulation. Rev Neurol 32:1128-1131, 2001

2. Bazowski P, Gamrot J, Rudnik A, Konopka M: Analysis of selected prognostic factors in patients with ruptured cerebral aneurysms operated-on in the early period. Neurol Neurochir Pol Suppl 1:2528, 1992

3. Bohnstedt BN, Nguyen HS, Kulwin CG, Shoja MM, Helbig GM, Leipzig TJ, Payner TD, Cohen-Gadol AA: Outcomes for clip ligation and hematoma evacuation associated with 102 patients with ruptured middle cerebral artery aneurysms. World Neurosurg 80:335-341, 2013

4. Carrera E, Schmidt JM, Oddo M, Fernandez L, Claassen J, Seder D, Lee K, Badjatia N, Connolly ES Jr, Mayer SA: Transcranial Doppler for predicting delayed cerebral ischemia after subarachnoid hemorrhage. Neurosurgery 65:316-323, 2009

5. Charpentier C, Audibert G, Guillemin F, Civit T, Ducrocq X, Bracard $\mathrm{S}$, Hepner H, Picard L, Laxenaire MC: Multivariate analysis of predictors of cerebral vasospasm occurrence after aneurysmal subarachnoid hemorrhage. Stroke 30:1402-1408, 1999

6. Chotai S, Ahn SY, Moon HJ, Kim JH, Chung HS, Chung YG, Kwon $\mathrm{TH}$ : Prediction of outcomes in young adults with aneurysmal subarachnoid hemorrhage. Neurol Med Chir (Tokyo) 53:157-162, 2013

7. Disney L, Weir B, Grace M: Factors influencing the outcome of aneurysm rupture in poor grade patients: A prospective series. Neurosurgery 23:1-9,1988

8. Drake CG, Hunt WE, Sano K, Kassell N, Teasdale G, Pertuiset B, DeVilliers JC: Report of World Federation of Neurological Surgeons Committee on a Universal Subarachnoid Hemorrhage Grading Scale. J Neurosurgery 68:985-986, 1988

9. Fisher CM, Kistler JP, Davis JM: Relation of cerebral vasospasm to subarachnoid hemorrhage visualised by computerised tomographic scanning. Neurosurgery 6:1-9, 1980
10. Germanson TP, Lanzino G, Kongable GL, Torner JC, Kassell NF: Risk classification after aneurysmal subarachnoid hemorrhage. Surg Neurol 49:155-163, 1998

11. Gomis P, Rousseaux P, Jolly D, Graftieaux JP: Initial prognostic factors of aneurysmal subarachnoid hemorrhage. Neurochirurgie 40:18-30, 1994

12. Haley EC, Kassell NF, Torner JC: The International cooperative study on the timing of aneurysm surgery. The North American experience. Stroke 23:205-214, 1992

13. Hop JW, Rinkel GJE, Algra A, van Gijn J: Initial loss of consciousness and risk of delayed cerebral ischemia after aneurysmal subarachnoid hemorrhage. Stroke 30:2268-2271, 1999

14. Jamjoom A, Jamjoom ZA, Stranjalis G, Cummins B, Torrens M: The outcome of surgery of aneurysmal subarachnoid haemorrhage. $\mathrm{Br}$ J Clin Pract 47:136-140, 1993

15. Jennett B, Bond M: Assessment of outcome after severe brain damage. A practical scale. Lancet 1:480-484, 1975

16. Kassel NF, Torner JC, Haley EC, Jane JA, Adams HP, Kongable GL: The international cooperative study on the timing of aneurysm surgery, part 1: Overall management results. J Neurosurg 73:1836, 1990

17. Kleinpeter G, Lehr S: Is hypertension a major risk factor in aneurysmal subarachnoid hemorrhage? Wien Klin Wochenschr 15:307-314, 2002

18. Lagares A, Gómez PA, Lobato RD, Alén JF, Alday R, Campollo $\mathrm{J}$ : Prognostic factors on hospital admission after spontaneous subarachnoid haemorrhage. Acta Neurochir (Wien) 143:665-672, 2001

19. Lagares A, Gómez PA, Alen JF, Lobato RD, Rivas JJ, Alday R, Campollo J, de la Camara AG: A comparison of different grading scales for predicting outcome after subarachnoid haemorrhage. Acta Neurochir (Wien) 147:5-16, 2005

20. Lin CL, Kwan AL, Howng SL: Surgical outcome of anterior communicating artery aneurysms. Kaohsiung J Med Sci 14:561568, 1998

21. Ogilvy CS, Carter BS: A proposed comprehensive grading system to predict outcome for surgical management of intracranial aneurysms. Neurosurgery 42: 959-970, 1998

22. Ohman J, Servo A, Heiskanen O: Risks factors for cerebral infarction in good-grade patients after aneurysmal subarachnoid hemorrhage and surgery: A prospective study. J Neurosurg 74:1420, 1991

23. Ostábal MI, Sanz C, Suárez MA, Salvo L, Millastre A: The study of prognostic factors of spontaneous subarachnoid hemorrhage. Rev Neurol 25:58-60, 1997

24. Pedraza S, Méndez-Méndez J: The prognostic value of computerized tomography in acute aneurysmal subarachnoid haemorrhages. Rev Neurol 39:359-363, 2004

25. Piazza P, Lisotto C, Querin F, Morassut S, Pomes A: Usefulness of computerized tomography in the prognosis of subarachnoid hemorrhage. Radiol Med 79:585-589, 1990

26. Rabb CH, Tang G, Chin LS: A statistical analysis of factors related to symptomatic cerebral vasospasm. Acta Neurochir (Wien) 127:27-31, 1994

27. Rosen DS, Macdonald RL: Grading of subarachnoid hemorrhage: Modification of the world World Federation of Neurosurgical Societies scale on the basis of data for a large series of patients. Neurosurgery 54:566-575, 2004 
28. Rosen DS, Macdonald RL: Subarachnoid hemorrhage grading scales: A systematic review. Neurocrit Care 2:110-118, 2005

29. Rosengart AJ, Schultheiss KE, Tolentino J, Macdonald RL: Prognostic factors for outcome in patients with aneurysmal subarachnoid hemorrhage. Stroke 38:2315-2321, 2007

30. Samaha E, Rizk T, Nohra G, Mohasseb G, Okais N: Intracranial arterial aneurysm: From diagnosis to treatment. A retrospective study of 46 surgically treated cases. J Med Liban 46:122-125, 1998

31. Schöller K, Massmann M, Markl G, Kunz M, Fesl G, Brückmann $\mathrm{H}$, Pfefferkorn T, Tonn JC, Schichor C: Aneurysmal subarachnoid hemorrhage in elderly patients: Long-term outcome and prognostic factors in an interdisciplinary treatment approach. $J$ Neurol 260:1052-1060, 2013
32. Shimoda M, Oda S, Tsugane R, Sato O: Prognostic factors in delayed ischaemic deficit with vasospasm in patients undergoing early aneurysm surgery. Br J Neurosurg 11:210-215, 1997

33. Shiue I, Arima H, Hankey GJ, Anderson CS: Location and size of ruptured intracranial aneurysm and serious clinical outcomes early after subarachnoid hemorrhage: A population-based study in Australasia. Cerebrovasc Dis 31:573-579, 2011

34. Vlak MH, Rinkel GJ, Greebe P, Greving JP, Algra A: Lifetime risks for aneurysmal subarachnoid haemorrhage: Multivariable risk stratification. J Neurol Neurosurg Psychiatry 84:619-623, 2013

35. Wong GK, Poon WS: Clinical, transcranial Doppler ultrasound, radiological features and, prognostic significance of delayed cerebral ischemia. Acta Neurochir Suppl 115: 9-11, 2013 